\title{
Assessing Feasibility of an Early Childhood Intervention Using Mobile Phones Among Low-Income Mothers of Newborns: Qualitative Interview Study
}

Donglan Zhang ${ }^{1}$, PhD; Lan Jin², PhD; Di Liang ${ }^{3}$, PhD; Ruijin Geng ${ }^{4}$, MPH; Yun Liu ${ }^{5}$, MD; Yu Ling ${ }^{5}$, MD; Fan Jiang $^{6,7^{*}}, \mathrm{MD}, \mathrm{PhD}$; Yunting Zhang ${ }^{6 *}, \mathrm{PhD}$

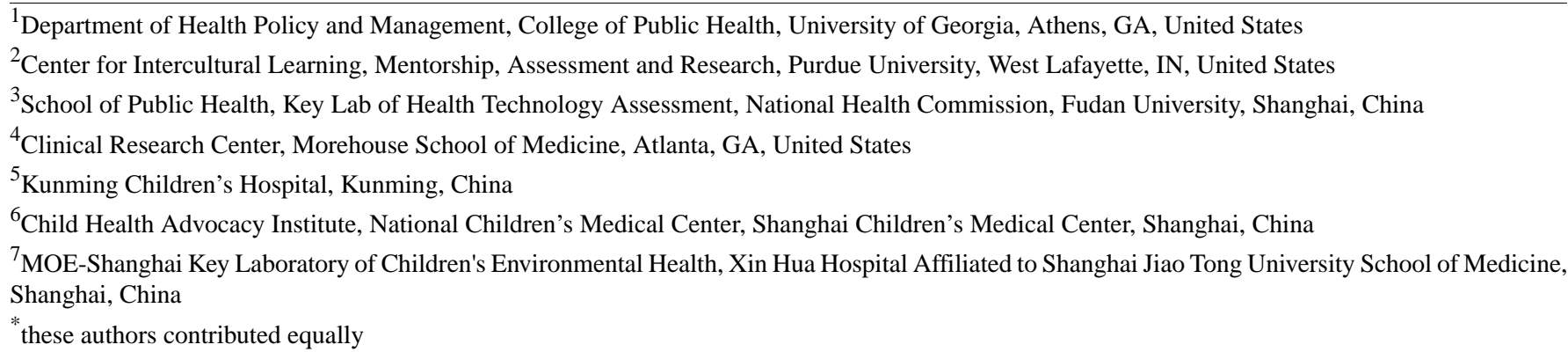

\section{Corresponding Author:}

Yunting Zhang, $\mathrm{PhD}$

Child Health Advocacy Institute, National Children's Medical Center

Shanghai Children's Medical Center

1678 Dongfang Road, Pudong

Shanghai

China

Phone: 86213862606

Email: zhangyunting@scmc.com.cn

\section{Abstract}

Background: Many children aged younger than 5 years living in low- and middle-income countries are at risk for poor development. Early child development (ECD) programs are cost-effective strategies to reduce poverty, crime, school dropouts, and socioeconomic inequality. With the spread of low-cost mobile phones and internet access in low- and middle-income countries, new service delivery models such as mobile phone-aided interventions have a great potential to improve early childhood development.

Objective: This study aimed to identify the beliefs on importance of ECD, feasibility of a proposed intervention using mobile phones and factors that may affect the usability of the intervention among mothers of newborns in a poverty-stricken area in southwestern China.

Methods: We conducted an in-depth, semistructured interview study of 25 low-income mothers of newborns recruited from two county hospitals in Yunnan Province. We applied the health belief model and cultural competence theories to identify the facilitators, barriers, and preferences among the target population for parenting knowledge.

Results: The results showed that the participants had low health literacy and high perceived needs for learning ECD knowledge. At the same time, they experienced several barriers to learning parenting information and following evidence-based instructions including having limited time, limited financial resources, and different opinions on childcare among family members. Many participants preferred to receive personalized messages tailored to their specific needs and preferred videos or graphics to text only in the messages. Many favored a separate module to support postpartum mental health.

Conclusions: The study assessed the acceptability of an early childhood intervention using mobile phones to meet the needs of the target population based on their beliefs, traits, and preferences and provided suggestions to refine the intervention to improve its usability. 


\section{KEYWORDS}

mobile health; interview; health belief model; early child development

\section{Introduction}

Early child development (ECD) has been shown to link with long-term health outcomes and well-being. Between 2004 and 2010, the number of children aged younger than 5 years who were at risk for poor development in low- and middle-income countries (LMICs) decreased from 279.1 million to 249.4 million [1-4]. There were 17.43 million at-risk children in China, and geographic disparities remained significant [1]. Prevalence of developmental delays in a low-income rural county in Northeast China was found to increase from $13.4 \%$ when the infants reached 6 to 12 months to $50.4 \%$ when they reached 24 to 30 months, while in most urban areas of China this prevalence remained under $10 \%[5,6]$. In certain regions of China, risk factors for developmental delays such as inadequate learning resources and activities were prevalent [7]. A household survey conducted among a representative sample of children aged 3 to 6 years in southwestern China found that $72 \%$ of the primary caregivers had not played with their children and $47 \%$ did not read to them in the past year [8].

ECD programs are cost-effective strategies to reduce poverty, crime, school dropouts, and socioeconomic inequality [9-12]. Targeted interventions have been implemented in the poorest areas of China focusing on nutrition supplement and early stimulation [13]. Parenting education provided in health check-ups, home visiting, and ECD centers have shown to be efficacious in some pilot studies [7]. However, it is challenging to scale up those programs due to limited resources available for a population of huge density, especially in remote areas where medical professionals are in short supply.

Currently, with the spread of low-cost mobile phones and internet access in LMICs, new service delivery models such as mobile phone-aided interventions (mHealth) have a great potential to influence ECD at the population level [14,15]. Short message services (text messages) and smartphone apps have proven to be successful in changing parents' beliefs and behaviors surrounding early child development. The intervention for parenting education covers a wide range of topics such as breastfeeding, nutrition, developmental milestones, anticipatory guidance, language and cognition-oriented activities, car seats, fire safety, etc. However, it has been found that compared with well-off families, caregivers with lower income, education, and literacy were less likely to enroll in mHealth programs, so the programs were of less benefit to the low-income people [16].

Previous studies identified possible incentives for low-income people to engage in mHealth programs, including financial incentives and need for better health for their children. However, barriers were also found such as culture and beliefs, limited battery life of mobile phones combined with the lack of readily available electricity, rates of interrupted mobile phone services, mistrust or stronger desire to preserve privacy, and lower technological literacy [16-19]. These issues must be elucidated and addressed before well-designed interventions can reach their intended audience and produce meaningful public health outcomes. Previous reviews have found that most effective public health programs are based on an understanding of the health behaviors and the contexts in which they occur with behavior change theories [20]. The health belief model (HBM), one of the most widely used theoretical models of health behaviors, has been applied most often for health concerns that are prevention-related and asymptomatic, where beliefs are as important or more important than overt symptoms [21]. As early child development lies more on the desire of parents of achieving better health and development rather than just management of certain diseases, we believe it is most suitable for our study.

This study aimed to identify the demand for ECD knowledge, acceptability of a promising ECD intervention using mobile phones, and factors that may affect the usability of the intervention among mothers of newborns in a poverty-stricken region of China. We employed a qualitative research method in this study because the rich data obtained through this method regarding participants' perceptions, preferences, and barriers are highly aligned with the study's purpose and scope. Results from this study will be used to support the design and implementation of the ECD intervention using mobile phones.

\section{Methods}

\section{Interview Sites}

In March 2019, we conducted 25 semistructured in-depth interviews among mothers of newborns recruited from two county hospitals in Yunnan Province, southwestern China: the Maternal and Child Health Hospital in Nanjian County and the People's Hospital in Jinggu County, both large hospitals where the majority of infants in the two counties were delivered. These two counties compose China's most poverty-stricken area based on the percentage of people below the national poverty line. The study was approved by the institutional review board at the University of Georgia (STUDY00005670).

\section{Theoretical Framework}

We applied the HBM and cultural competence theories to identify the preferences and barriers among the target population for receiving and practicing evidence-based parenting knowledge [22]. HBM has been used in a broad range of behavioral interventions including interventions to increase screening, reduce risky behavior, and improve adherence to medication regimen [23-26]. In its latest version, the key constructs of the model include cues to action and self-efficacy and perceived susceptibility, severity, benefits, and barriers [27]. Studies have shown that parental perception regarding the healthy development of their young children often involves perceived barriers to take action [28-30]. Behavioral change will not occur if parents' perceived barriers outweigh perceived benefits [31].

In addition, although our target population did not have language barriers when reading ECD messages, they might have cultural beliefs that were not consistent with the evidence that supports 
child healthy development. Culturally competent approaches recognize and respect the cultural beliefs, norms, and values of the target population and aim to improve effectiveness of the intervention $[32,33]$. Therefore, in our theoretical framework, cultural beliefs and norms were included as a modifying factor (Figure 1).

Figure 1. Theoretical framework based on the health belief model.

\begin{tabular}{|l|}
\hline \multicolumn{1}{|c|}{ Individual perception } \\
\hline -Perceived \\
susceptibility - \\
mothers believe that \\
their children may \\
experience \\
malnutrition, neglect \\
and lack of stimulation \\
\\
\end{tabular}

\section{Study Sites and Participants}

The inclusion criteria were the study participants should be in good health with no severe delivery complications or clinical diagnosis of postpartum depression and have a healthy infant aged less than 1 month.

Two physicians assisted in identifying and recruiting potentially eligible participants through the hospital wards. The 25 participants were recruited in the local hospitals through criterion sampling. We reached sample saturation with 25 participants, until a point where additional interviews did not develop new theoretical insights. In other words, sampling was stopped when the data were repetitive and our research questions had been answered. To examine their eligibility for the study based on the criteria, electronic medical records were retrieved to scan for any recorded delivery complications or diagnosed depression. Informed consents were obtained from all participants who met the inclusion criteria and agreed to participate in the study.

\section{Data Collection}

Two trained interviewers (DZ and YZ) conducted the in-depth interviews in private rooms at the hospitals. We developed an interview guide based on the theoretical framework (Figure 1) pertaining to the design of the mobile health intervention. These topics included (1) mothers' individual perceptions about the importance of avoiding adversities in the early years; (2) benefits and barriers when feeding and nurturing newborns according to recommendations sent over the phone; (3) family socioeconomic status, family structure, relationship, beliefs, and values related with adhering to the recommendations; (4) concerns about privacy; and (5) preferences for the frequency of receiving messages. During the interview, the Edinburgh Postnatal Depression Scale, Chinese version, was used to evaluate mothers' mental health status [34,35]. Participants were shown sample text messages and were asked questions about the messages. The message included about 600 Chinese characters and two pictures with four sections: (1) weekly achievement, showing easily identifiable developmental milestones; (2) weekly care, providing relevant information on baby's daily care; (3) weekly game, showing examples of age-paced games and parent-child activities including playing games, singing nursery rhymes, reading, and drawing; and (4) weekly question and answer, providing answers to common questions asked by parents. The interview was designed to begin with sociodemographic questions followed with questions according to each construct in the HBM.

Interviews were conducted on a one-on-one basis. Each interview lasts approximately 60 to 90 minutes. To aid in recruitment, ¥100 (US \$15 in 2019) was provided to each participant. All interviews were tape recorded with participant permission.

\section{Data Analysis}

Interviews were transcribed verbatim and entered into qualitative analysis software NVivo 12 (QSR International). A coding structure based on the interview guide was iteratively developed to label specific content from the interviews. The transcripts were coded separately by two members of the study team (DL and RG). After coding, the two team members met to discuss the results and resolve any disagreements in coding by consensus. 


\section{Results}

\section{Participant Demographic Characteristics}

Table 1 shows the characteristics of the 25 participants. Their average age was 28 years. More participants lived in urban regions than in rural regions (56\% [14/25] vs 44\% [11/25]). Most participants (10/25, 40\%) were ethnically Han Chinese, $32 \%(8 / 25)$ were $\mathrm{Yi}$, and $16 \%$ (4/25) were Dai Chinese. Overall, $48 \%(12 / 25)$ of newborns were male. The majority of the infants' primary caregivers $(18 / 25,72 \%)$ were mothers, while $12 \%(3 / 25)$ were grandparents. A total of $40 \%(10 / 25)$ of the mothers finished middle school, and $28 \%$ (7/25) obtained some college education, while $16 \%(4 / 25)$ finished only elementary school. Half of the participants $(13 / 25,52 \%)$ were unemployed, and $28 \%(7 / 25)$ had a full-time job; $48 \%(12 / 25)$ of participants reported that the main source of family income was from their husband. About half $(13 / 25,52 \%)$ of the participants had household income below $¥ 5000$ (US \$750) per month, whereas $52 \%(13 / 25)$ of them reported they were willing to spend between $¥ 1000$ (US \$150) and $¥ 2000$ (US \$300) on childcare, and $28 \%(7 / 25)$ reported they were willing to spend more than $¥ 2000$ (US \$300). A majority of the participants $(23 / 25,92 \%$ ) were not receiving public financial aid. Most $(23 / 25,92 \%)$ were married, and $40 \%(10 / 25)$ lived in extended families with 7 or more family members. 
Table 1. Participant demographic characteristics $(n=25)$.

\begin{tabular}{ll}
\hline Characteristics & Value \\
\hline Age in years, mean (SD) & $28.08(6.55)$
\end{tabular}

Region, $n$ (\%)

Urban or township

$14(56)$

Rural

Race/ethnicity, n (\%)

$\begin{array}{ll}\text { Han } & 10(40) \\ \text { Yi } & 8(32) \\ \text { Hui } & 2(8) \\ \text { Dai } & 4(16) \\ \text { Yao } & 1(4)\end{array}$

Sex of the newborn, $n(\%)$

Male

$12(48)$

Female

No response

Primary caregiver of the baby, $n(\%)$

Self (mother of the baby)

18 (72)

Grandparents of the baby

Self and grandparents

No response

Education of the mother, $n(\%)$

Elementary school

Middle school

$10(40)$

High school

1 (4)

Some college

Four-year college

Employment of the mother, $n(\%)$

Full-time employment

Self-employed

No employment

Household main income source, n (\%)

Double income

Husband's income

Family farm or business

Income from parents-in-law

No response

Estimated household income per month ( $¥)$, n (\%)

$<5000$

5000-10,000

$\geq 10,000$

Expenditures on the baby per month ( $¥), \mathbf{n}(\%)$

$<1000$

$1000-2000$

$13(52)$ 


\begin{tabular}{ll}
\hline Characteristics & Value \\
\hline$\geq 2000$ & $7(28)$ \\
Don't know & $3(12)$ \\
Receiving government financial aid, $\mathbf{n}(\boldsymbol{\%})$ & $2(8)$ \\
$\quad$ Yes & $23(92)$ \\
No & $23(92)$ \\
Marital status, $\mathbf{n}(\boldsymbol{\%})$ & $1(4)$ \\
Married & $1(4)$ \\
Married but live separately & \\
Married with no official certificate & $5(20)$ \\
Number of family members in the household, $\mathbf{n}(\boldsymbol{\%})$ & $10(40)$ \\
3 or 4 & $10(40)$ \\
5 or 6 & \\
7 and more & \\
Number of children in the household, $\mathbf{n}(\boldsymbol{\%})$ & $5(20)$ \\
1 & $18(72)$ \\
3 & $2(8)$ \\
\hline
\end{tabular}

\section{Participant Health, Work, and Breastfeeding Behavior}

Table 2 shows participant health status and lifestyle. All participants self-reported having good health. Most participants had a low risk of postpartum depression with a depression scale score below 13, but 6 people (24\%) had a relatively high risk of depression, although no clinical diagnosis of depression was reported. A total of 76\% (19/25) of participants reported light to moderate workload for doing housework, and 64\% (16/25) of participants would spend more time on childcare than on other things, while 20\% (5/25) reported that they would spend more time on family business, housework, or farm work. Most participants $(16 / 25,64 \%)$ had no difficulty in breastfeeding, while $28 \%$ (7/25) did not start breastfeeding, and one participant reported having no breastfeeding plan because she had hepatitis B. A majority of the participants $(18 / 25,72 \%)$ planned to breastfeed for 6 months to 1 year, and 12\% (3/25) planned to breastfeed for less than 6 months. 
Table 2. Mothers' health, work, and breastfeeding behavior $(\mathrm{n}=25)$.

\begin{tabular}{|c|c|}
\hline Characteristic & Value, $\mathrm{n}(\%)$ \\
\hline Self-reported health status, good health & $25(100)$ \\
\hline \multicolumn{2}{|l|}{ Depression scale } \\
\hline Yes $(\geq 13)$ & $6(24)$ \\
\hline No $(<13)$ & $19(76)$ \\
\hline \multicolumn{2}{|l|}{ Housework load } \\
\hline Light & $19(76)$ \\
\hline Heavy & $4(16)$ \\
\hline Don't do housework & $1(4)$ \\
\hline No response & $1(4)$ \\
\hline \multicolumn{2}{|l|}{ Time allocation on childcare and other things } \\
\hline Spend more time on business, housework, or farm work & $5(20)$ \\
\hline Spend more time on childcare & $16(64)$ \\
\hline Spend equal amount of time on childcare and work & $3(12)$ \\
\hline No response & $1(4)$ \\
\hline \multicolumn{2}{|l|}{ Breastfeeding status } \\
\hline Having no difficulty in breastfeeding & $16(64)$ \\
\hline Not having started breastfed & $7(28)$ \\
\hline Formula feeding & $1(4)$ \\
\hline No plan to breastfeed & $1(4)$ \\
\hline \multicolumn{2}{|l|}{ Breastfeeding plan } \\
\hline 6 months & $3(12)$ \\
\hline 6 months to 1 year & $18(72)$ \\
\hline More than 1 year & $2(8)$ \\
\hline No plan to breastfeed & $2(8)$ \\
\hline
\end{tabular}

\section{Interview Themes}

\section{Perceived Needs for Learning Early Child Development Knowledge}

Around half of participants were concerned about baby's health issues such as having a cold, fever, acute diseases, adverse reaction to vaccination, tobacco exposure, sleep, and other illnesses, and 3 participants worried about baby's behavioral problems-for instance, they expressed concerns about their child being spoiled by grandparents and developing bad habits (Multimedia Appendix 1). Two participants expressed the need to learn baby's cognitive development, and another 2 participants worried about safety issues. Most participants thought it was necessary to learn ECD knowledge. When asked to describe interesting topics in ECD, most participants mentioned baby's growth and milestones, nutrition, breastfeeding, and complementary feeding. Some participants mentioned that they were interested in parent-child interactions and baby's social-emotional development. Several participants were interested in mental health support for mothers. Sample responses included: "I want to learn whether his growth is normal, and how parents should interact with him." "My first child often caught cold probably because I did not have enough breastmilk. For my second child I want to know how to prevent cold" and "I would like to learn about safety issues. My home is near the street. It is dangerous for the kids. I worry about safety when he starts to learn walking."

Some participants reported that they did not learn parenting knowledge before giving birth to this child, whereas many learned parenting knowledge from books and the internet, and only 2 reported having learned ECD knowledge from health care professionals. A majority of the participants perceived that they had limited ECD knowledge, and some didn't feel the need to learn parenting knowledge. One response was, "I want to know more about how to take care of my baby when he is getting old, and how to help him recover without taking medicines when he is sick." Some participants thought that parenting information they found online was inconsistent, and they perceived the necessity to promote the child's early development.

\section{Perceived Usefulness and Barriers to Learn and Practice Parenting Knowledge}

Many participants were willing to learn ECD knowledge from health professionals. One response was, "I want to learn parenting knowledge from experts. If it doesn't take a lot of 
time, I am willing to follow experts' suggestions. I can read the messages after my baby sleeps at night. I don't have time during the daytime."

Some participants responded that they did not have barriers in following experts' advice, but many expressed that they had difficulties following experts' suggestions because they had limited time and financial resources, limited experiences, and their children did not react as expected or they had different opinions with family members. Some examples were, "I have to go to work. I may not have time to follow experts' suggestions on childcare," "I think the biggest obstacle for me is that if the experts recommend a new-brand formula which is very expensive, I will not follow their suggestions," and "I may not follow the experts' recommendation when my child's grandparents have different opinions on parenting."

\section{Maternal Self-Efficacy}

Many participants illustrated that they made decisions on childcare by themselves or together with their husband. Some participants responded that their husband made the decision about childcare, and some illustrated that their mother-in-law made the decision.

Overall, most participants said they had good relationships with family members, while some expressed that they did not have good relationships with their parents-in-law. Many participants said they preferred to follow health professionals' suggestions in caring for their babies when there was a conflict between experts' and family members' suggestions, while 2 participants replied that they preferred to follow family members' suggestions. However, only 4 participants were willing to communicate with their family members the knowledge they learned from professionals or persuade them to take the evidence-based advice, and some participants said they would not persuade family members because their parents had limited ability to understand the knowledge.

\section{Preferences for the Design of the Intervention}

Almost all participants had a smartphone and had access to internet on their phones, and only 1 person shared the smartphone with her husband. Almost all participants preferred to receive messages via smartphone apps, and half of them preferred to receive the messages once a week, while 9 participants preferred to receive the messages every day or twice a week. Overall, most participants responded that they would keep and share the messages and won't delete them. A majority of the participants were willing to receive personalized information based on their child's characteristics. One response was, "I would prefer to receive personalized suggestions. My child is different from other kids." However, several mothers preferred to receive general messages and stated that they would like to keep their baby's information confidential.

When asked if they were willing to search for answers from health professionals when having questions, many participants preferred to consult with pediatricians at the county hospital, some preferred to communicate via phone with professionals in large hospitals remotely, and some of them would search for answers online. Most of them expressed that they did not trust

village doctors and were more likely to ask for opinions from doctors at larger health care facilities.

\section{Raised Suggestions to Modify the Message Contents}

When shown the sample text message, 11 mothers spent on average less than 3 minutes to read one message, and 10 mothers spent 3 to 5 minutes to read one message, and 4 of them spent more than 5 minutes.

Some participants emphasized that they were very interested in the weekly game section. One participant illustrated, "parent-child interaction is very beneficial for the healthy development of the child's personality." Another participant described that "I like the section of parent-child interaction. Every mom enjoys playing games with their child." Some mothers expressed that they liked the weekly care section on nurturing, teething, or mood management.

Most participants considered the message understandable, and some indicated that they preferred videos and pictures to text. A few said that they did not understand even though they were literate enough to read the text. One response was, "it may be better if the messages can be conveyed via a video. I can easily understand the messages by watching a video." Further, 3 participants suggested that the messages should include a platform for interaction between receivers and health care professionals. One response was, "I like the weekly question and answer section because I would like to have a platform where specific questions are answered by the experts."

\section{Discussion}

\section{Principal Findings}

This study focused on assessing feasibility of an ECD intervention using mobile phones to meet the needs of mothers of newborns based on their beliefs, traits, and preferences. By interviewing 25 mothers, we enhanced our understanding of the necessary elements for an ECD intervention to be acceptable to low-income communities and determined the factors that may affect the usability of the intervention. From the demographic information, the samples in our study were distributed evenly in rural and urban areas and covered a variety of races. The majority of mothers we interviewed reported under $¥ 5000$ (US \$750) estimated household income per month. Overall, the samples in our study fitted our targeted ECD intervention, which was mothers of newborn children from the poverty-stricken area.

The results indicated that mothers living in high-poverty regions of China had strong perceived demand for understanding the risk of poor childhood development. They had limited knowledge on ECD and needed evidence-based information. They were concerned that children may experience health problems such as malnutrition and poor cognitive development. From this perspective, we believe that the general guidance on how to deal with common disease and malnutrition as well as anticipatory guidance on development should be easily accessed in the mHealth program to increase the motivation of use. Furthermore, they realized that parent-child interaction played a vital role in ECD. The participants expressed their interests to learn how to read books and play games with their child. 
Therefore, education information on those aspects should be maintained in the mobile phone-aided intervention.

In terms of likelihood of action, the participants believed that learning parenting knowledge would help them better understand the child's needs. However, perceived barriers such as having limited time and resources, different opinions in childcare among family members, and distrust of village doctors exist, which may affect whether participants follow the evidence. Therefore, it might help to expand the mobile health program to incorporate training for local doctors and community health workers, in order to build a trustworthy relationship between parents and local health professionals [36]. In addition, many participants lived with their parents, who may influence their decision making, and several participants reported that their husband or mother-in-law made decisions on childcare. Although some indicated that they would prefer to follow the evidence-based information, they were still concerned that their parents or parents-in-law would insist on the traditional beliefs. A potential approach to address this barrier is to create a shared account among family members so that everyone in a household can learn ECD knowledge. It is worth noting that some participants had a high risk of postpartum depression based on the cutoff point of our screening tool, and messages/sections on postpartum mental health support should be incorporated in the ECD intervention.

As for the feasibility and ideas on the ECD app content, we found most participants had access to the internet and smartphones, thus the mobile health program was feasible for this population. However, the participants had relatively low breastfeeding rate/attempts and low health literacy, and thus multimedia (eg, video, graphics, and text) and plain language should be applied to make the content more understandable. Visuals help make the information more persuasive and memorable [37], which is particularly important for people with low health literacy [38]. Plain language with a concise and organized writing style helps participants better understand the messages. Moreover, since the participants indicated that they didn't have much time due to childcare responsibilities, text message that took more than 5 minutes to read might be lengthy for them. Prior studies have proven that media-assisted interventions, such as video episodes, can increase the reach and reduce the cost and time for parent education; these are also parents' strongest preferences $[39,40]$. Therefore, instead of using text, we plan to create 1-minute videos in the new designed app conveying parenting knowledge and early childhood interventions to decrease learning time and make learning more convenient and attractive for the parents.

\section{Limitations}

We did not specifically interview mothers whose children are at older ages, and their needs for parenting education could be different with those moms who have a newborn child. However, we did interview several moms who already have an elder child, so we were able to retrieve some information on this end.

\section{Conclusion}

Our study proposed that mHealth should be considered as one of the techniques in interventions on ECD due to its feasibility, low cost, and potential to cover a wide range of the population. This was the first study to ever understand the beliefs and barriers for a mobile phone-based intervention to improve ECD in a high-poverty region in southwestern China. We conclude that even in poverty-stricken areas, both the technology and the health literacy meet the requirement for the implementation of mHealth programs. Furthermore, this study brought out some potential ideas to make it more feasible when applied on the ground. The results of the study will aid in the development of potentially effective early childhood programs in underserved regions in LMICs.

\section{Acknowledgments}

The study was funded by a Global Collaboration Research Grant from the Office of Research and Office of International Education, College of Public Health, University of Georgia, Athens, Georgia. We thank Dr Zi Zhaohua, Maternal and Child Health Center of Nanjian County, and Dr Liu Kaihua, People's Hospital of Jingu County, for coordinating the field study and assisting with patient recruitment.

\section{Authors' Contributions}

FJ designed the framework and coordinated the fieldwork. For any further questions regarding the study design and content, please contact: fanjiang@ shsmu.edu.cn.

\section{Conflicts of Interest}

None declared.

\section{Multimedia Appendix 1}

Interview questions and answers based on the health belief model. [DOCX File, $20 \mathrm{~KB}-\underline{\text { Multimedia Appendix 1] }}$

\section{References}

1. Lu C, Black MM, Richter LM. Risk of poor development in young children in low-income and middle-income countries: an estimation and analysis at the global, regional, and country level. Lancet Glob Health 2016 Dec;4(12):e916-e922 [FREE Full text] [doi: 10.1016/S2214-109X(16)30266-2] [Medline: 27717632] 
2. Dua T, Tomlinson M, Tablante E, Britto P, Yousfzai A, Daelmans B. Darmstadt GL: Global research priorities to accelerate early child development in the sustainable development era. Lancet Global Health 2016;4(12):e887-e889. [doi: $10.1016 /$ S2214-109X(16)30218-2]

3. Yu DM, Zhao LY, Yang ZY, Chang SY, Yu WT, Fang HY, et al. Comparison of undernutrition prevalence of children under 5 years in China between 2002 and 2013. Biomed Environ Sci 2016 Mar;29(3):165-176 [FREE Full text] [doi: 10.3967/bes2016.021] [Medline: 27109127]

4. Chang S, He W, Chen C. [The growth characteristics of children under 5 in the past 15 years]. Wei Sheng Yan Jiu 2006 Nov;35(6):768-771. [Medline: 17290763]

5. Cui Y, Gao JQ, Yue A, Tang L, Luo RF, Scott R. [Early childhood development and risk factors in rural China: a cohort study]. Zhonghua Er Ke Za Zhi 2018 Feb 02;56(2):103-109. [doi: 10.3760/cma.j.issn.0578-1310.2018.02.006] [Medline: 29429197]

6. Wenjie S, Yunting Z, Qingmin L, Yanrui J, Qi Z, Fan J. Study on the status quo of early child development in eight provinces of China. 2019. URL: https://kns.cnki.net/KCMS/detail/detail.aspx?dbcode=CJFQ\&dbname=CJFDLAST2019\&filename= ERTO201904005\&v=MTcyODNmWWJHNEg5ak1xNDIGWV1SOGVYMUx1eFITN0RoMVQzcVRyV00xRnJDVVI3c WZZK1J0RmlEblVyekFJRC8= [accessed 2020-04-22]

7. Jin X, Sun Y, Jiang F, Ma J, Morgan C, Shen X. "Care for Development” intervention in rural China: a prospective follow-up study. J Dev Behav Pediatr 2007 Jun;28(3):213-218. [doi: 10.1097/dbp.0b013e31802d410b] [Medline: 17565288]

8. Liang X, Fu Y, Zhang Y. Challenges and opportunities: early childhood education in Yunnan. Washington: World Bank Group; 2013. URL: http://documents.worldbank.org/curated/en/730951468011141807/pdf/ ACS69150REPLAC00Box385296B00PUBLIC0.pdf [accessed 2020-04-15]

9. Karoly L, Kilburn M. Rand Corporation. 2006. Early childhood interventions: proven results, future promise URL: https:/ /www.rand.org/content/dam/rand/pubs/monographs/2005/RAND_MG341.pdf [accessed 2020-04-15]

10. Nores M, Barnett WS. Benefits of early childhood interventions across the world: (under) investing in the very young. Econ Educ Rev 2010 Apr;29(2):271-282. [doi: 10.1016/j.econedurev.2009.09.001]

11. Aos S, Lieb R, Mayfield J, Miller M. Benefits and costs of prevention and early intervention programs for youth. Olympia: Washington State Institute for Public Policy; Sep 17, 2004.

12. Reynolds AJ, Temple JA, Robertson DL, Mann EA. Long-term effects of an early childhood intervention on educational achievement and juvenile arrest: a 15-year follow-up of low-income children in public schools. JAMA 2001 May 09;285(18):2339-2346. [doi: 10.1001/jama.285.18.2339] [Medline: 11343481$]$

13. Jiao X, Huo J, Sun J. Complementary food supplements interventions for 6 to 24 months old infants in poverty areas. Chin J Food Hygiene 2017. [doi: 10.13590/j.cjfh.2017.05.006]

14. Hurwitz LB, Lauricella AR, Hanson A, Raden A, Wartella E. Supporting Head Start parents: impact of a text message intervention on parent-child activity engagement. Early Child Devel Care 2015 Jan 06;185(9):1373-1389. [doi: 10.1080/03004430.2014.996217]

15. Fedele DA, Cushing CC, Fritz A, Amaro CM, Ortega A. Mobile health interventions for improving health outcomes in youth: a meta-analysis. JAMA Pediatr 2017 May 01;171(5):461-469. [doi: 10.1001/jamapediatrics.2017.0042] [Medline: 28319239]

16. Cunningham M, Bull S, McNulty MC, Colborn K, Chavez C, Berman S, et al. Does a text-messaging program to promote early childhood development reach the highest risk families? Mhealth 2018;4:55 [FREE Full text] [doi:

10.21037/mhealth.2018.11.03] [Medline: 30596079]

17. van Heerden A, Sen D, Desmond C, Louw J, Richter L. App-supported promotion of child growth and development by community health workers in Kenya: feasibility and acceptability study. JMIR Mhealth Uhealth 2017 Dec 05;5(12):e182 [FREE Full text] [doi: 10.2196/mhealth.6911] [Medline: 29208588]

18. Diese M, Kalonji A, Izale B, Villeneuve S, Kintaudi NM, Clarysse G, et al. Community-based maternal, newborn, and child health surveillance: perceptions and attitudes of local stakeholders towards using mobile phone by village health volunteers in the Kenge Health Zone, Democratic Republic of Congo. BMC Public Health 2018 Mar 05;18(1):316 [FREE Full text] [doi: 10.1186/s12889-018-5186-2] [Medline: 29506500]

19. Gibson DG, Ochieng B, Kagucia EW, Were J, Hayford K, Moulton LH, et al. Mobile phone-delivered reminders and incentives to improve childhood immunisation coverage and timeliness in Kenya (M-SIMU): a cluster randomised controlled trial. Lancet Glob Health 2017 Dec;5(4):e428-e438 [FREE Full text] [doi: 10.1016/S2214-109X(17)30072-4] [Medline: 28288747]

20. Glanz K, Rimer BK. Theory at a Glance: A Guide for Health Promotion Practice. Scotts Valley: CreateSpace Independent Publishing Platform; 2005.

21. Glanz K, Bishop DB. The role of behavioral science theory in development and implementation of public health interventions. Annu Rev Public Health 2010;31:399-418. [doi: 10.1146/annurev.publhealth.012809.103604] [Medline: 20070207]

22. Fjeldsoe BS, Marshall AL, Miller YD. Behavior change interventions delivered by mobile telephone short-message service. Am J Prev Med 2009 Feb;36(2):165-173. [doi: 10.1016/j.amepre.2008.09.040] [Medline: 19135907]

23. Harrison JA, Mullen PD, Green LW. A meta-analysis of studies of the Health Belief Model with adults. Health Educ Res 1992 Mar;7(1):107-116. [Medline: 10148735] 
24. Montanaro EA, Bryan AD. Comparing theory-based condom interventions: health belief model versus theory of planned behavior. Health Psychol 2014 Oct;33(10):1251-1260. [doi: 10.1037/a0033969] [Medline: 23977877]

25. Jones CJ, Smith H, Llewellyn C. Evaluating the effectiveness of health belief model interventions in improving adherence: a systematic review. Health Psychol Rev 2014;8(3):253-269. [doi: 10.1080/17437199.2013.802623] [Medline: 25053213]

26. Ahadzadeh AS, Pahlevan SS, Ong FS, Khong KW. Integrating health belief model and technology acceptance model: an investigation of health-related internet use. J Med Internet Res 2015;17(2):e45 [FREE Full text] [doi: 10.2196/jmir.3564] [Medline: 25700481]

27. Glanz K, Rimer B, Viswanath K. Health Behavior and Health Education: Theory, Research, and Practice. Hoboken: John Wiley \& Sons; 2008.

28. Pocock M, Trivedi D, Wills W, Bunn F, Magnusson J. Parental perceptions regarding healthy behaviours for preventing overweight and obesity in young children: a systematic review of qualitative studies. Obes Rev 2010 May;11(5):338-353. [doi: 10.1111/j.1467-789X.2009.00648.x] [Medline: 19780989]

29. Yin HS, Dreyer BP, Vivar KL, MacFarland S, van Schaick L, Mendelsohn AL. Perceived barriers to care and attitudes towards shared decision-making among low socioeconomic status parents: role of health literacy. Acad Pediatr 2012;12(2):117-124 [FREE Full text] [doi: 10.1016/j.acap.2012.01.001] [Medline: 22321814]

30. Girio-Herrera E, Owens JS, Langberg JM. Perceived barriers to help-seeking among parents of at-risk kindergarteners in rural communities. J Clin Child Adolesc Psychol 2013;42(1):68-77. [doi: 10.1080/15374416.2012.715365] [Medline: 22963042]

31. Atkinson NL, Permuth-Levine R. Benefits, barriers, and cues to action of yoga practice: a focus group approach. Am $\mathbf{J}$ Health Behav 2009;33(1):3-14. [doi: 10.5993/ajhb.33.1.1] [Medline: 18844516]

32. Huey SJ, Tilley JL, Jones EO, Smith CA. The contribution of cultural competence to evidence-based care for ethnically diverse populations. Annu Rev Clin Psychol 2014;10:305-338. [doi: 10.1146/annurev-clinpsy-032813-153729] [Medline: $\underline{24437436}$ ]

33. Moon RY, Hauck FR, Colson ER, Kellams AL, Geller NL, Heeren T, et al. The effect of nursing quality improvement and mobile health interventions on infant sleep practices: a randomized clinical trial. JAMA 2017 Jul 25;318(4):351-359 [FREE Full text] [doi: 10.1001/jama.2017.8982] [Medline: 28742913]

34. Cox JL, Holden JM, Sagovsky R. Detection of postnatal depression: development of the 10-item Edinburgh Postnatal Depression Scale. Br J Psychiatry 1987 Jun;150:782-786. [Medline: 3651732]

35. Lee DT, Yip SK, Chiu HF, Leung TY, Chan KP, Chau IO, et al. Detecting postnatal depression in Chinese women. Validation of the Chinese version of the Edinburgh Postnatal Depression Scale. Br J Psychiatry 1998 May;172:433-437. [Medline: 9747407]

36. Mishra SR, Neupane D, Briffa TG, Kallestrup P. mHealth plus community health worker interventions: the future research agenda. Lancet Diabetes Endocrinol 2016 May;4(5):387-388. [doi: 10.1016/S2213-8587(16)30001-8] [Medline: 27106686]

37. Royston G, Hagar C, Long L, McMahon D, Pakenham-Walsh N, Wadhwani N. Mobile health-care information for all: a global challenge. Lancet Glob Health 2015 Jul;3(7):e356-e357 [FREE Full text] [doi: 10.1016/S2214-109X(15)00054-6] [Medline: 26087979]

38. Houts PS, Doak CC, Doak LG, Loscalzo MJ. The role of pictures in improving health communication: a review of research on attention, comprehension, recall, and adherence. Patient Educ Couns 2006 May;61(2):173-190. [doi: 10.1016/j.pec.2005.05.004] [Medline: 16122896]

39. Hall CM, Bierman KL. Technology-assisted Interventions for parents of young children: emerging practices, current research, and future directions. Early Child Res Q 2015;33:21-32 [FREE Full text] [doi: 10.1016/j.ecresq.2015.05.003] [Medline: 27773964]

40. McClure C, Cunningham M, Bull S, Berman S, Allison MA. Using mobile health to promote early language development: a narrative review. Acad Pediatr 2018;18(8):850-854. [doi: 10.1016/j.acap.2018.07.010] [Medline: 30098442]

\author{
Abbreviations \\ ECD: early child development \\ HBM: health belief model \\ LMIC: low- and middle-income countries \\ mHealth: mobile health
}


Edited by G Eysenbach; submitted 24.11.19; peer-reviewed by P Chaovalit, S Song; comments to author 01.01.20; revised version received 10.02.20; accepted 29.03.20; published 28.05.20

Please cite as:

Zhang D, Jin L, Liang D, Geng R, Liu Y, Ling Y, Jiang F, Zhang Y

Assessing Feasibility of an Early Childhood Intervention Using Mobile Phones Among Low-Income Mothers of Newborns: Qualitative Interview Study

JMIR Form Res 2020;4(5):e17179

URL: http://formative.jmir.org/2020/5/e17179/

doi: $\underline{10.2196 / 17179}$

PMID: $\underline{32463374}$

(CDonglan Zhang, Lan Jin, Di Liang, Ruijin Geng, Yun Liu, Yu Ling, Fan Jiang, Yunting Zhang. Originally published in JMIR Formative Research (http://formative.jmir.org), 28.05.2020. This is an open-access article distributed under the terms of the Creative Commons Attribution License (https://creativecommons.org/licenses/by/4.0/), which permits unrestricted use, distribution, and reproduction in any medium, provided the original work, first published in JMIR Formative Research, is properly cited. The complete bibliographic information, a link to the original publication on http://formative.jmir.org, as well as this copyright and license information must be included. 